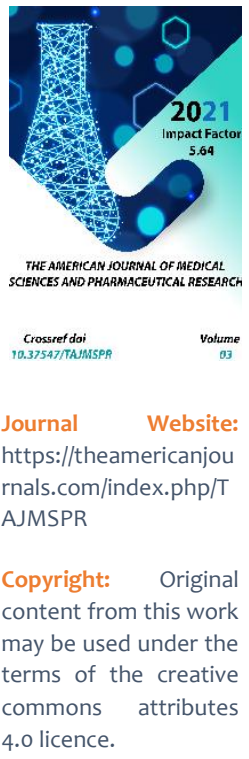

\title{
The Importance Of Immunoprophylaxis For Tuberculosis (BCG Vaccination)
}

\section{Bayramgul Sadikovna Jumamuratova}

Assistant Of The Department Of Public Health, Public Health Management Of Bukhara State Medical Institute, Bukhara, Uzbekistan

\section{ABSTRACT}

Vaccination is a costly activity, as it involves coverage of a wide population. Methods to assess the effectiveness of immunoprophylaxis and the quality of preventive (anti-epidemic) measures are discussed in this context.

\section{KEYWORDS}

Immunoprophylaxis, Tuberculosis, Prevention.

\section{INTRODUCTION}

Throughout its 215-year history, vaccine prophylaxis has proven to be extremely effective in preserving human life and reducing morbidity and mortality. According to WHO experts, vaccination and clean drinking water are the only proven measures to have a real impact on public health. Vaccination is the most effective and cost-effective preventive measure known in modern medicine).

The TB vaccine was created in 1921 by French scientists Calmette and Guerin, hence its name (Bacille Calmette-Guerin, abbreviated to BCG or BCG in Russian). In its first years of use, the vaccine was used to induce artificial immunity in newborns by injecting it with the mother's expressed milk. Later, the cutaneous method of vaccination was developed and introduced. Currently, the vaccine is administered intradermally $(c / k)$ to the forearm in the maternity hospital. The vaccination is repeated at the age of 6-7 years and, if necessary, at the age of 14-15 years. 


\section{MATERIALS AND METHODS}

Tuberculosis ("Tbs") is a dangerous problem. One area of effective prevention is mass active immunisation of the population with TB vaccine $B C G$ (according to the vaccination calendar: the first vaccination is given at 3 to 7 days of age in the maternity ward, subsequent revaccinations in the early and late school age). Regular passive immunisation with TB serum is also recommended for prisoners as well as for staff such as supervisors and warders in prison units. This is a specific prophylaxis that allows the disease to be completely prevented. As a non-specific prophylaxis it is advisable to take care of your health, to avoid colds in the bronchopulmonary system (lungs, bronchi, trachea, larynx and nasopharynx) and the excretory organs (kidneys and bladder), and to keep your immune system in working order. Immunomodulators can only be used for this purpose after a doctor's prescription. The easiest and most affordable non-drug immunomodulator is a good diet and healthpromoting exercise. Koch's bacillus (named after the discoverer - German microbiologist, professor at Berlin University, Robert Koch. for this discovery he was awarded the Nobel Prize in the early 2oth century). So, Koch's bacillus is very sensitive and dies when the air is ozonized and quartzed (treated with a quartz lamp) for half an hour. Switching on the bactericidal quartz lamp is always and must always be done outside the presence of people, as UV radiation is harmful to the eyes and skin. In the eighties there was a theory, but not experimentally confirmed, that a group of modified saprophytic pathogens causes diseases similar to tuberculosis lesions on radiographs, but which are much milder, because the morphology lacks specific tuberculosis caseous (curd-like) inflammation. Harmful predisposing factors to Tbs are, in addition to contact with an active patient, also smoking, alcoholism, poor nutrition, prolonged stay in damp, cold, poorly ventilated rooms. Every year more than 1.5 million people die of tuberculosis in the world. According to the Uzbek Health Ministry, there are 42.9 TB patients for every 100,000 people, and the mortality rate is 1.6. More than 118 billion UZS will be invested in fighting the infection by 2021. To combat the stigmatisation of TB patients, multidisciplinary teams have been set up in the oblasts in conjunction with Project Hope, an international medical organisation, which includes previously infected people, representatives of vulnerable groups, mahalla committees and active women who carry out outreach work among the population. This is outreach to vulnerable groups and is often carried out by people who have experienced the burden of TB on themselves or their loved ones and know how to make contact with a risk group. Outreach workers talk about the infection and the importance and necessity of treatment. They offer free check-ups and initiate a course of medication if necessary. "Children do not excrete or excrete little sputum with mycobacteria, so other testing methods are used for children. The WHO is introducing new immunological tests that can detect the presence of infection in a child's body and the development of the disease. The tests can be taken by those who come to a TB facility of their own volition and by members of a risk group. A special criterion for selecting children has been developed for this purpose. In addition, he reported that a new treatment with a combination of isoniazid and rifampicin has been developed to prevent persons with latent tuberculosis from developing tuberculosis. People in contact with infected people take the drugs once a week for three 
months. The organisation predicts that if this type of prevention is introduced throughout the republic and if $85 \%$ of those covered complete the course of medication, the incidence of tuberculosis will fall by $8 \%$ a year in the future. WHO recalls that the risk group is primarily made up of people who have had contact with patients with cantogenesis (who excrete Mycobacterium tuberculosis bacteria in their sputum). People living with HIV are 2040 times more likely to develop active TB disease. People with diabetes or organ transplant survivors, smokers and frequent drinkers, migrants from countries with high disease rates, people in correctional facilities, and sex workers are also at risk. The TB bacterium lives for up to 15 minutes in the sunlight outdoors. In the shade, it takes a few weeks, in water it can live for months, and in humid conditions the infection lives for years. According to the WHO, TB is transmitted only by airborne droplets. Extrapulmonary TB is usually accompanied by purulent processes which cannot enter the lungs. A person with extrapulmonary TB can be said to be $99 \%$ safe. In this case, the infection initially enters the lungs and then settles in another organ. One week after starting treatment, patients are not contagious. If the bacterium is sensitive to isoniazid, for example, the drug kills up to $98 \%$ of mycobacteria within two days. It takes 6 to 20 months to kill the remaining $2 \%$ of the dormant bacteria. This is why it is so important not to stop treatment. Thanks to the USAID programme, more than 400 laboratory specialists have been trained in quality management, infection control since 2015. Laboratories in several regions of Uzbekistan are provided with the necessary testing materials. In 2018 alone, more than 2,000 specialists received training. The National Centre for Innovative and Distance Learning in
Tashkent and its branch in Bukhara were also opened. Six more branches are scheduled to open this year. USAID also trains journalists and outreach workers to identify those infected with Koch's bacillus among at-risk groups to properly convey information about tuberculosis. Vaccinations are given by a specially trained nurse. The BCG vaccination is needed to prevent tuberculosis in children. It does not protect against infection by the TB pathogen, but it protects against the transition from latent infection to manifest disease (in about $70 \%$ of all people who have been vaccinated) and almost $100 \%$ of children against serious forms of TB - TB meningitis, TB in the bones and joints and serious forms of TB in the lungs. It is the use of BCG vaccine that has enabled a significant reduction in the incidence of TB in children in general, and in particular, for many years now, despite the difficult social situation, we have not seen any cases of TB meningitis in vaccinated children. The $B C G$ vaccination is usually given in the maternity home on the fourth day of the baby's life, in the left shoulder, at the border of its upper and middle thirds.

The $B C G$ vaccine is an attenuated vaccine strain that cannot cause tuberculosis, but allows immunity to be developed against the disease. Since immunity against TB is only developed when the causative agent or its vaccine replacement is present in the body, it is not possible to make a killed vaccine, so all countries use the same BCG vaccine from different manufacturers (many parents often ask about imported vaccines, because they think they are better). Moreover, the domestic vaccine is better because both vaccinators and paediatricians have a lot of experience with it. In addition, imported vaccines can take quite a long time to be stored at customs or in 
unsuitable conditions, and because the vaccine is live, storage conditions must be very strict. There is a variant of $B C G$ vaccine, $B C G-M$, which has half the germs in it as the standard vaccine. BCG-M vaccine is used to vaccinate weakened and prematurely born babies and is usually not given at the hospital, but rather at the place where the baby will be taken from the hospital. The BCG vaccine, unlike, say, the DPT vaccine, is generally well-tolerated, but complications from the vaccination can occur, and we remind parents of this here so they know what to look out for. Immunity after BCG vaccination lasts for 6-7 years, so all children who have a negative Mantoux at age 7 are offered a second BCG vaccination. Now, in the wave of the fashionable anti-vaccination craze, some parents believe that vaccinations are harmful because they contain phenol, mercury and the like. The fact is that the BCG vaccine does contain preservatives, but you can't make a live vaccine without it. Tuberculosis vaccination the main factor determining the occurrence and course of the disease is the state of the body's defenses. Unfavorable social conditions and previous weakening of the body due to other, especially chronic diseases, contribute to the emergence of tuberculosis. The effectiveness of the vaccine - the results are mixed, and vary from country to country. In the UK, studies on 50,000 children showed an $80 \%$ reduction in the risk of infection after vaccination. The results in the US are less impressive. However, recent studies have shown that the risk of pulmonary TB is halved after vaccination and mortality is reduced by $71 \%$. The results of our studies show that unvaccinated children get TB disease 12-15 times more often than those vaccinated on time and according to all the rules. TB vaccination in vaccinated children induces immunity to TB infection. Once a vaccinated child has received BCG, the tuberculosis mycobacteria usually do not cause the severe forms of tuberculosis resulting from primary infection (tuberculous meningitis, miliary tuberculosis, cereous pneumonia, large lung infiltrates with formation of primary caverns). However, BCG vaccine does not protect against tuberculosis infection, i.e. against penetration of mycobacteria by aerogenic or elementary route and development of primary tuberculosis infection, which is accompanied by local forms of primary tuberculosis in 7 to $10 \%$ of those infected. In vaccinated children, primary infection is usually invisible and often undetectable or diagnosed with an initial tuberculin reaction, which remains positive for life in those who have had a primary infection. Such persons are referred to as infected with tuberculosis.

the number of people infected with tuberculosis is more than $1 \%$ - To children Vaccination is recommended:

- In countries where who have a family history of tuberculosis. BCG vaccination is given to newborns; if the vaccination was not given in the maternity ward, it should be taken care of during the first 6 weeks of the infant's life. A tuberculin test (Mantoux) is not necessary until six weeks of age. In children older than 6 weeks of age the vaccine should only be given when the reaction to the tuberculin is negative, in order to avoid complications due to possible infection. BCG vaccine is not effective if it is administered to an already infected person.

\section{Contraindications to $B C G$ vaccination}

Absolute (permanent):

- Primary immunodeficiencies 
- HIV infection

- Malignant blood diseases

- Neoplasms

- Had a severe reaction to a previous BCG injection.

- Tuberculosis

Temporary:

- Intrauterine infections

- Hemolytic disease

- Severe prematurity (<2000 g).

- Skin diseases

- High-dose therapy with corticosteroids or Immunosuppressants;

Contraindications to neonatal vaccination:- IIIV degree prematurity;

- Prematurity III-IV degree; - Intrauterine hypotrophy III-IV degree;

- Intrauterine infection;

- Purulent-septic diseases;

- Haemolytic disease in newborns (moderate-severe and severe forms);

- Generalized skin lesions;

- Acute diseases;

- Generalised BCG infection diagnosed in other children in the family;

To revaccination of children:

- Infected with tuberculosis or have a history of tuberculosis;

- A positive or dubious Mantoux reaction;

- Complicated reactions to a previous BCG vaccination (keloid scars, lymphadenitis, etc.);

- Acute illnesses and acute chronic diseases;

- Allergic illnesses that have become acute;

- Malignant blood diseases and neoplasms;

- Secondary immunodeficiencies, treatment with immunosuppressant drugs (based on Secondary immunodeficiencies; treatment with immunosuppressants (specialist opinion following immunological evaluation);

- Primary immunodeficiencies, HIV infection;

- Pregnancy.

\section{CONCLUSIONS}

The BCG vaccination is therefore needed to prevent TB in children. It does not protect against infection with the tuberculosis pathogen, but it does protect against the progression of latent infection to manifest disease (in about $70 \%$ of those vaccinated), and it protects almost $100 \%$ of children against severe forms of tuberculosis - tuberculous meningitis, TB of the bones and joints and severe forms of pulmonary tuberculosis. It is the use of BCG vaccine that has enabled a significant reduction in the incidence of TB in children in general, and in particular, for many years now, despite the difficult social situation, we have not seen any cases of TB meningitis in vaccinated children. The main tasks of general outpatient clinics are to examine patients for TB and to refer them to a TB dispensary in a timely manner. General outpatient clinics perform a clinical minimum (pulmonary fluorography, sputum smear examination, tuberculin test, blood and urine tests) when examining patients for tuberculosis. Sanitary and epidemiological surveillance system activities for prevention and detection of tuberculosis. The work of the Sanitary and Epidemiological Surveillance Committee and its subdivisions on prevention of tuberculosis in their area of responsibility includes the following:

- Carrying out specific prophylaxis, early and timely detection of tuberculosis, strengthening the bacteriological service 
to improve the epidemiological situation of tuberculosis;

- Control over sanitary condition of industrial enterprises, child and adolescent institutions, implementation of epidemiological regime in anti-tuberculosis institutions and in foci of tuberculosis infection.

\section{REFERENCES}

1. Шиянова, А. Е., Дмитриева, Л. Н., \& Карнаухов, И. Г. (2016). Источники информации о заболеваемости в мире инфекционными болезнями, значимыми для санитарной охраны территории российской федерации. Обзор Интернет-Ресурсов. Эпидемиология и инфекционные болезни. Актуальные вопросы, (6), 62-66.

2. Электронный ресурс. Factsheet for health professionals - malaria. Stockholm: European Centre for Disease Prevention and Control; 2014 r. (http://www.ecdc.europa.eu/en/health topics/malaria/factsheethealthprofessionals/Pages/factsheet_ health_professionals.aspx).\%3D\%3D\&la ng=ru. Дата обращения: февраль 2021 r.

3. Halstead, S. B., \& Papaevangelou, G. (1980). Transmission of dengue 1 and 2 viruses in Greece in 1928. The American journal of tropical medicine and hygiene, 29(4), 635-637.

4. Vahidova, A. M. (2019). Fungi of the genus pacilomyces in human echinococcosis. World Science: Problems and Innovations, 186-190.

5. Shomurodov, K. E. (2010). Peculiarities of cytokine balance in gingival fluid at odontogenicphlegmon of maxillofacial area. The doctor-aspirant.-2010.-42 (5.1).-C, 187-192.

6. Tillyashaykhov M. N., Rakhimov N. M. Khasanov Sh. T., (2019). Features of Clinical Manifestation of the bladder cancer in young people. Doctor Bulletin, Samarkand, - №2. - pp. 108-113

7. Ilkhomovna, K. M., Eriyigitovich, I. S., \& Kadyrovich, K. N. (2020). Morphological Features Of Microvascular Tissue of The Brain At Hemorrhagic Stroke. The American Journal of Medical Sciences and Pharmaceutical Research, 2(10), 53-59.

8. Ziyadullaev, S., Elmamatov, O., Raximov, N., \& Raufov, F. (2020). Cytogenetic and immunological alterations of recurrent bladder cancer. European Journal of Molecular \& Clinical Medicine, 7(2), 1877-1883.

9. Куклев, Е. В. (1999). Количественная оценка эпидемического потенциала природных очагов чумы: Автореф. дисс.... A. М. н.

10. Askling, H. H., Bruneel, F., Burchard, G., Castelli, F., Chiodini, P. L., Grobusch, M. P., ... \& Schlagenhauf, P. (2012). Management of imported malaria in Europe. Malaria journal, 11(1), 1-15.

11. Seiwald, S., Simeon, A., Hofer, E., Weiss, G., \& Bellmann-Weiler, R. (2020). Tularemia Goes West: Epidemiology of an Emerging Infection in Austria. Microorganisms, 8(10), 1597.

12. Grizhebovskiil, G. M., Velibekov, A. S., Mamedov, S. D., \& Popov, V. A. (1991). The characteristics of a cholera outbreak in Pushkino District, the Azerbaijan SSR. Zhurnal Mikrobiologii, Epidemiologii i Immunobiologii, (4), 2930. 